\title{
Increasing value and reducing waste in biomedical research: librarians are listening and are part of the answer
}

David Moher and colleagues ${ }^{1}$ asked who is listening to calls to increase value and reduce waste in biomedical research. They documented the response of the different stakeholder groups identified in the Lancet Research: Increasing Value, Reducing Waste Series ${ }^{2-6}$ and the Lancet REWARD (REduce research Waste And Reward Diligence) Campaign. However, there is one group that has not been explicitly discussed: biomedical librarians and information scientists. ${ }^{7}$ The role of librarians in supporting biomedical research could be substantially expanded by acknowledging their skills and embracing their involvement in research departments, funding bodies, and journal editorial offices. It is time for librarians and their essential skills to move beyond the confines of the library.

First, a librarian could be embedded within every biomedical research department, or at least within every research team, and contribute to two of the areas highlighted in the Lancet Series. Given librarians' expertise in systematic reviews, ${ }^{8,9}$ the librarian could conduct all the literature searches required by the department to ensure that searches are comprehensive and rigorously designed, conducted, documented, and reported. During preparations for funding applications the librarian could help to assess the extent of uncertainty and identify relevant ongoing research.

Second, librarian involvement in peer review could help to ensure the quality and reliability of published research. Biomedical journals might consider the role of a literature search reviewer who could review possible inadequacies in the literature search process for submitted papers. Such a position would be similar to the role of the statistical reviewer that is already well-established in many biomedical journals. Indeed, Jefferson and Deeks ${ }^{10}$ have mentioned a potential role for "methodological expert reviewers", although they do not specify librarians within this grouping.

Third, research funders could make greater use of librarians during peer review of funding applications. As highlighted in the recommendations of the Lancet Research: Increasing Value, Reducing Waste Series, ${ }^{1}$ grant applicants are increasingly required to provide evidence that the research question for which they are applying for funding reflects a demonstrable uncertainty that requires addressing. Librarians could be involved in peer reviewing the search strategies used to identify evidence in support of funding applications to identify any issues, including relevant evidence that has been missed by the literature search. Involvement of literature search specialist reviewers would ensure that only those proposals that have shown reliable and robust evidence of uncertainty would be considered for funding, thereby reducing waste in research.

Establishing the three roles outlined above could contribute to more meticulous funding decisions and to the publication of better research. Waste in biomedical research is a serious issue with no single solution. Biomedical librarians are listening and are ready to respond to the calls to increase value and reduce waste. To fully 
realise the contribution that health science librarians could make, other stakeholder groups identified in the Lancet REWARD campaign would benefit from recognising and utilising their essential skills.

\section{Shona Kirtley}

EQUATOR Network, Centre for Statistics in Medicine, Nuffield Department of Orthopaedics, Rheumatology and Musculoskeletal Sciences, University of Oxford, Oxford OX3 7LD, UK shona.kirtley@csm.ox.ac.uk

I declare no competing interests.

1 Moher $D$, Glasziou $P$, Chalmers I, et al. Increasing value and reducing waste in biomedical research: who's listening? Lancet 2016; 387: 1573-86.

2 Chalmers I, Bracken MB, Djulbegovic B, et al. How to increase value and reduce waste when research priorities are set. Lancet 2014; 383: 156-65.

3 Ioannidis JP, Greenland S, Hlatky MA, et al. Increasing value and reducing waste in research design, conduct, and analysis. Lancet 2014; 383: 166-75. 4 Al-Shahi Salman R, Beller E, Kagan J, et al. Increasing value and reducing waste in biomedical research regulation and management. Lancet 2014;

383: $176-85$.

5 Chan AW, Song F, Vickers A, et al. Increasing value and reducing waste: addressing inaccessible research. Lancet 2014; 383: 257-66.

6 Glasziou P, Altman DG, Bossuyt P, Boutron I, Clarke M, Julious S, et al. Reducing waste from incomplete or unusable reports of biomedical research. Lancet 2014; 383: 267-76.

7 Kirtley S. Can librarians contribute to increasing value and reducing waste in medical research? 2014. http://www.equator-network.org/2014/02/28/canlibrarianscontribute-to-increasing-value-and-reducing-waste-in-medicalresearch/ (accessed April 8, 2016).

8 Rethlefsen ML, Farrell AM, Osterhaus Trzasko LC, Brigham TJ. Librarian coauthors correlated with higher quality reported search strategies in general internal medicine systematic reviews. J Clin Epidemio/ 2015; 68: 617-26. 9 Mathisen M, Hjelmesaeth J, Aune E, Ruddox V, Otterstad JE.

The Journal of the Norwegian Medical Association should impose stricter requirements to literature searches. Tidsskr Nor Laegeforen. 2013; 133: 1615-17. 10 Jefferson T, Deeks J. The use of systematic reviews for editorial peer reviewing: a population approach. In: Godlee F, Jefferson T, eds. Peer review in health sciences, 2nd edn. London: BMJ Publishing Group, 2003: 297-308. 